\title{
Corrigendum: Evaluation of General Synthesis Procedures for Bioflavonoid-Metal Complexes in Air-Saturated Alkaline Solutions
}

\author{
Yuanyong Yao*, Meng Zhang, Laibing He, Yunyang Wang and Shixue Chen* \\ Tongren Key Laboratory for Modernization Research, Development and Utilization of Traditional Chinese Medicine and \\ National Medicine, School of Material and Chemical Engineering, Tongren University, Tongren, China
}

Keywords: dihydromyricetin, flavonoids, bioflavonoid-metal complexes, alkaline conditions, superoxide anion, HPLC, UV-visible spectrophotometer, transition metal ions

\section{OPEN ACCESS \\ Edited by: \\ $\mathrm{Hu} \mathrm{Li}$ \\ Guizhou University, China}

Reviewed by:

Zhichao Jin,

Guizhou University, China

*Correspondence: Yuanyong Yao

chyyyy@gztrc.edu.cn

Shixue Chen

tongrencsx01@126.com

Specialty section:

This article was submitted to

Organic Chemistry,

a section of the journal

Frontiers in Chemistry

Received: 13 August 2020

Accepted: 24 August 2020

Published: 11 November 2020

Citation:

Yao Y, Zhang M, He L, Wang Y and

Chen S (2020) Corrigendum:

Evaluation of General Synthesis

Procedures for Bioflavonoid-Metal Complexes in Air-Saturated Alkaline Solutions. Front. Chem. 8:594058. doi: 10.3389/fchem.2020.594058

\section{A Corrigendum on}

Evaluation of General Synthesis Procedures for Bioflavonoid-Metal Complexes in Air-Saturated Alkaline Solutions

by Yao, Y., Zhang, M., He, L., Wang, Y., and Chen, S. (2020). Front. Chem. 8:589. doi: 10.3389/fchem.2020.00589

In the original article, there was a mistake in the legends for Figures 3, 4, 7, and 8 as published. In these Figures, marks such as a, b, c, d, e, f, and $g$ have not been explained. The updated legends appear below.

Figure 3. (A) UV-vis spectra and (B) main peak positions of DHM refluxed for different times. (a) DHM; (b-g) DHM refluxing for 30, 60, 90, 120, 150, and $180 \mathrm{~min}$.

Figure 4. (A) UV-vis spectra and (B) main peak positions of DHM stirred for different times at $\mathrm{pH}=8.2$. (a) DHM; (b-g) DHM stirring for 1,3,5, 10, 20, and $30 \mathrm{~min}$ in $\mathrm{pH} 8.2$.

Figure 7. EPR spectra of DHM in air-, nitrogen-, and oxygen-saturated alkaline solutions. (a) DHM only; (b) DHM + DMPO; (c-e) DHM + DMPO, in nitrogen-, air-, oxygen-saturated alkaline solution.

Figure 8. EPR spectra of superoxide-anion radical generation from DMSO reacted with a base in the presence of oxygen. (a) DMSO $+\mathrm{DMPO}+\mathrm{O}_{2}$; (b) $\mathrm{Na}^{+} \mathrm{PhO}^{-}+\mathrm{DMPO}+\mathrm{O}_{2}$; (c) $\mathrm{Na}^{+} \mathrm{PhO}^{-}+\mathrm{O}_{2}$; (d) $\mathrm{DMSO}+\mathrm{Na}^{+} \mathrm{PhO}^{-}+\mathrm{O}_{2}$; (e) $\mathrm{DMSO}+\mathrm{Na}^{+} \mathrm{PhO}^{-}+\mathrm{DMPO}+\mathrm{O}_{2}$

The authors apologize for this error and state that this does not change the scientific conclusions of the article in any way. The original article has been updated.

Copyright () 2020 Yao, Zhang, He, Wang and Chen. This is an open-access article distributed under the terms of the Creative Commons Attribution License (CC BY). The use, distribution or reproduction in other forums is permitted, provided the original author(s) and the copyright owner(s) are credited and that the original publication in this journal is cited, in accordance with accepted academic practice. No use, distribution or reproduction is permitted which does not comply with these terms. 